\title{
Minocycline reduces experimental muscle hyperalgesia induced by repeated nerve growth factor injections in humans: A placebo-controlled double-blind drug-crossover study
}

James S. Dunn, Saad Nagi and David A. Mahns

The self-archived postprint version of this journal article is available at Linköping University Institutional Repository (DiVA):

http://urn.kb.se/resolve?urn=urn:nbn:se:liu:diva-165406

N.B.: When citing this work, cite the original publication.

Dunn, J. S., Nagi, S., Mahns, D. A., (2020), Minocycline reduces experimental muscle hyperalgesia induced by repeated nerve growth factor injections in humans: A placebo-controlled double-blind drug-crossover study, European Journal of Pain. https://doi.org/10.1002/ejp.1558

Original publication available at:

https://doi.org/10.1002/ejp.15.58

Copyright: Wiley (12 months)

http://eu.wiley.com/WileyCDA/ 
Minocycline reduces experimental muscle hyperalgesia induced by repeated nerve growth factor injections in humans: A placebo-controlled double-blind drug-crossover study

Running head: Minocycline reduces muscle hyperalgesia

James. S. Dunn ${ }^{1}$, Saad. S. Nagi ${ }^{1,2} *$ \& David. A Mahns ${ }^{1 *}$

${ }^{1}$ School of Medicine, Western Sydney University, Locked Bag 1797, Penrith, NSW 2751, Australia.

${ }^{2}$ Department of Biomedical and Clinical Sciences, Center for Social and Affective Neuroscience, Linköping University, 58183, Sweden.

*These authors contributed equally to this work as co-last authors.

Corresponding author: James S. Dunn

Locked Bag 1797, Penrith, NSW 2751, Australia

+61246203707

James.dunn@westernsydney.edu.au

Submission category: Original article

Funding sources: This study was funded by the Western Sydney University School of Medicine under the Research Training Program (RTP). The funding body had no role in the design or execution of this study.

Conflicts of interest: The authors declare no conflicts of interest

Significance: In a double-blind placebo-controlled drug-crossover study, the common antibiotic minocycline was found to reduce the muscle hyperalgesia induced by intramuscular injection of nerve growth factor. The results of the study showed that both concomitant (pre-emptive) and delayed administration of minocycline can ameliorate the onset and facilitate the resolution of experimentally induced muscle hyperalgesia.

This article has been accepted for publication and undergone full peer review but has not been through the copyediting, typesetting, pagination and proofreading process, which may lead to differences between this version and the Version of Record. Please cite this article as doi: 10.1002/ejp.1558

This article is protected by copyright. All rights reserved 


\begin{abstract}
\end{abstract}
Background: Hyperalgesia is a heightened pain response to a noxious stimulus and is a hallmark of many common neuropathic and chronic pain conditions. In a double-blind placebo-controlled drug-crossover trial the effects of concomitant and delayed minocycline treatment on the initiation and resolution of muscle hyperalgesia were tested.

Methods: An initial cohort ( $n=10)$ received repeated injections (5 $\mu \mathrm{g}$ : days 0,2 and 4 ) of nerve growth factor (NGF) in the flexor carpi ulnaris muscle of the forearm and pressure pain thresholds were collected at day 0 (control), day 7 (peak) and day 14 (recovery). A second cohort $(n=18)$ underwent an identical procedure, however, half received a placebo between days 0-7 before switching to minocycline from days 7-14 (P1/M2), while the remaining subjects received minocycline (day 0: $200 \mathrm{mg}$ then $100 \mathrm{mg}$ b.i.d. for 7 days) before switching to placebo (M1/P2).

Results: The initial cohort exhibited a diffuse muscular pain hypersensitivity with a decrease in pressure pain thresholds at day 7 before a partial return to normalcy at day 14 . The $\mathrm{P} 1 / \mathrm{M} 2$ treatment group exhibited an identical peak in hypersensitivity at day 7 , however, after switching to minocycline in week 2 showed a significant reduction in muscle hyperalgesia compared to the initial cohort at day 14 . The M1/P2 treatment group had significantly less ( $\sim 3 \%$ ) hyperalgesia at day 7 compared to the other groups.

Conclusions: The study indicates that the administration of minocycline can reduce experimentally induced muscle pain regardless of the time of administration.

This article is protected by copyright. All rights reserved 


\section{Introduction}

Despite growing knowledge of pain mechanisms in humans, the efficacy of current pain treatments remains limited (Moore 2013). Nerve growth factor (NGF) is a naturally occurring neurotrophic factor which shifts from signalling nerve growth and survival during development to signalling inflammation and injury in the adult nervous system (Lewin et al., 2014; Pezet and McMahon 2006) with NGF synthesis in skeletal muscle increasing under pathological conditions (Amano et al., 1991; Hayashi et al., 2011; Murase et al., 2010). The pro-inflammatory role of NGF and the identification of elevated levels of NGF in many conditions such as arthritis (Aloe et al., 1992; Halliday et al., 1998; Raychaudhuri and Raychaudhuri 2009) and fibromyalgia (Giovengo et al., 1999) has implicated NGF as a viable target for the treatment (Hefti et al., 2006; Kumar and Mahal 2012; Watson et al., 2008) and experimental modelling of chronic pain (Andersen et al., 2008; Bergin et al., 2015; Deising et al., 2012; Hayashi et al., 2013; Svensson et al., 2008).

Intramuscular administration of NGF produces a hyperalgesia (Andersen et al., 2008; Gerber et al., 2011; Hayashi et al., 2013; Svensson et al., 2003; Svensson et al., 2008) that can manifest as movement evoked pain and pain to palpation (Bergin et al., 2015). The longlasting (days to weeks) effects of NGF administration (Nie et al., 2009; Svensson et al., 2003) are thought to stem from the activation of a cascade of neurotrophic factor-mediated changes (Pezet and McMahon 2006; Priestley et al., 2002) including the upregulation of neuromodulators such as calcitonin gene-related protein and substance P (SP) (Malcangio et al., 1997) as well as enhanced responsiveness of ion channels (Pezet and McMahon 2006). With such widespread effects, NGF has been proposed as an experimental pain model of sustained elbow pain (Bergin et al., 2015), temporomandibular disorder (Svensson et al., 2003), and myofascial (Hayashi et al., 2013) and neuropathic pain (Rukwied et al., 2010).

We have previously shown that in healthy participants minocycline treatment prevents muscle hyperalgesia and cutaneous allodynia induced by repeated intramuscular injections of hypertonic saline (HS) (Samour et al., 2017). Minocycline is a second-generation, semisynthetic tetracycline, and is widely used as a broad-spectrum antibiotic (Strauss et al., 2007; Yong et al., 2004). Minocycline has been shown to reduce microglial activation (Tikka et al., 2001; Tikka and Koistinaho 2001) and given the identified role of microglia in neuropathic pain (Tsuda 2016), this reduction in microglial activation may cause a 
suppression of the pain response. Importantly, for potential therapeutic applications, minocycline is lipid-soluble and can penetrate the blood-brain barrier allowing it to act on the central nervous system (Brogden et al., 1975; Kielian et al., 2007; Yrjänheikki et al., 1999). Indeed, it has already been reported that minocycline administration in a clinical context can have beneficial effects in humans with improved functional recovery in patients with spinal cord injury (Casha et al., 2012) and a reduction of the neuropathic symptoms in patients with diabetic neuropathy (Syngle et al., 2014).

Based on the above observations, and our prior finding that minocycline prevented the development of muscle hypersensitivity (Samour et al., 2017), we hypothesised that minocycline would limit the development (when given pre-emptively on day 0 ) and reverse the established (when administration was delayed until day 7) muscle hypersensitivity induced by repeated injections of NGF. By working in a model system that mimics persistent pain hypersensitivity we will be able to evaluate the potential for minocycline to have efficacious translational effects in a clinical cohort within the context of muscle pain. To this point, the effects of minocycline were examined in a double-blind placebo-controlled drugcrossover study with treated individuals additionally compared to an untreated cohort.

\section{Methods}

Subjects with no reported history of musculoskeletal or neurological disorders were

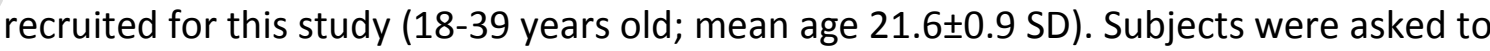
refrain from strenuous bouts of physical activity for at least 48 hours prior to commencement of the study so as not to sensitize any muscles, particularly in the forearm (Weerakkody et al., 2001). Informed written consent was obtained from each subject prior to commencement of the study. Across all experimental sessions, the subjects sat comfortably in a chair in a semi-reclined position. The study was approved by the Human Research Ethics Committee (approval number: H9190) of Western Sydney University in accordance with the Revised Declaration of Helsinki of 1975, as revised in 1983.

Figure 1 depicts a timeline of the study for all cohorts tested, indicating NGF injection schedule and sensory testing sessions as well as drug-crossover within cohort 2.

\section{*Insert figure 1 here*}

This article is protected by copyright. All rights reserved 


\section{NGF Injection}

Recombinant human $\beta$-NGF ( $5 \mu \mathrm{g}$; Peprotech, Rocky Hill, New Jersey, USA) was dissolved in a solution of $50 \mu \mathrm{L}$ of sterile water (Pfizer Australia Pty. Ltd., West Ryde, NSW, Australia). The NGF solution was injected as a bolus into the belly of the flexor carpi ulnaris (FCU) muscle of the non-dominant arm at a point approximately $8-9 \mathrm{~cm}$ distal to the medial epicondyle of the elbow, adjusted in proportion to the arm length of the subject. Injections of $5 \mu \mathrm{g}$ were administered on days 0, 2 and 4 of the study using a BD Ultra-Fine II syringe (BD ANZ, Sydney, Australia). Injections were approximately 48 hours apart and repeated at the same site to minimize the number of needle stick injury sites across the muscle test area (FCU). Before each injection, the tenderness of the test site and the effect of previous NGF injection were determined through palpation of the muscle compartment.

A repeat NGF injection model was chosen as it has been shown to elicit a longer lasting reaction when compared to single injection models (Deising et al., 2012; Hayashi et al., 2013; Svensson et al., 2003) and ensure sustained hypersensitivity at day 14 (Hayashi et al., 2013). The interval between the repeat injections ( 48 hours) was chosen to mimic the timeline of our previous minocycline work which used repeated HS injections to evoke hypersensitivity (Samour et al., 2017).

\section{Testing Sites}

Testing was performed bilaterally across both FCU muscles due to a prior observation of bilateral muscle hyperalgesia in a longitudinal experimental pain model which involved repeated HS injections (Samour et al., 2017).

With subjects comfortably seated, a $6 \times 10 \mathrm{~cm}$ grid consisting of 15 points was drawn over the anteromedial/flexor compartment of both forearms overlying the FCU muscle. The 15-point grid was arranged with three columns running medial to lateral and five rows running proximal to distal with $2 \mathrm{~cm}$ separating each point (Figure 1). The grid was placed in such a manner that the centre point was the same site as the NGF injection (marked in red in Figure 1 and in bold throughout Figure 2).

Pressure pain threshold (PPT) testing 
Mechanical algometry was performed across both test sites (bilateral FCU) on three separate occasions to assess PPTs and the distribution of evoked muscle hyperalgesia from intramuscular NGF injections.

Initially, a force of $30 \mathrm{~N}$ for $\sim 3 \mathrm{~s}$ was applied at each grid point $(\mathrm{n}=15)$ across both test sites using a $1 \mathrm{~cm}^{2}$ rubber tip pressure gauge (Pain Test Model FPN 50 Algometer, Wagner Instruments, Greenwich, Connecticut, USA). If a participant reported pain at a point, then a progressively smaller force (in decrements of $5 \mathrm{~N}$ ) was applied until the subject no longer reported a painful percept. To mitigate the chance of central wind-up (an increase in neuronal excitability observed following repeated stimulation, Herrero, et al., 2000) an inter-stimulus interval of at least $10 \mathrm{~s}$ was used and threshold values were confirmed by testing adjacent and remote sites in a pseudo-random order before returning to the test site in question. The upper end of the PPT test range $(30 \mathrm{~N})$ was selected so as not to evoke a painful response in more than $\sim 30 \%$ of the population and aligns with reports in the literature $30 \mathrm{~N}$ is the approximate upper border of the innocuous pressure range (Chesterton et al., 2003). Methods for PPT evaluation are based on those previously reported in the literature (Nagi and Mahns 2013; Samour et al., 2017).

Testing intervals were arrived upon based on data collection from a pilot study, with thresholds collected on day 0 prior to NGF injection (control), day 7 after the first NGF injection where hypersensitivity was established, and 14 days after the first injection where threshold values remained significantly elevated compared to control.

\section{Follow-up testing}

Subjects were asked to return for a follow-up testing session at least 28 days after the initial NGF injection to ensure a full alleviation of muscle hyperalgesia and a return to normalcy. For this, an abridged sensory protocol was utilised with muscle palpation and pseudorandomised application of pressure algometry across the test site to ensure that there were no residual effects of NGF injections. As no subjects reported tenderness to palpation or algometry during the abridged protocol, a complete protocol (as outlined above) was not performed at this time point.

\section{Minocycline administration}

This article is protected by copyright. All rights reserved 
Based on the standard Australian prescribing practice and previous studies (Curtin et al., 2017; Pachman et al., 2017; Samour et al., 2017), minocycline was given orally as a 200mg loading dose followed by bidaily $100 \mathrm{mg}$ continuation doses. Minocycline and placebo (rice flour) tablets were formulated by a compounding chemist in opaque capsules and delivered in coded 'Minocycline trial' containers that were (other than the code) indistinguishable to the subjects and the experimenters.

The code linking the container number to the formulation of its contents was retained by the compounding chemist for the duration of data collection to ensure true double-blinding of the study.

\section{Cohort 1 - Untreated control}

Eleven subjects ( 4 females) were recruited for this arm of the study. These subjects received NGF injections in the absence of a pharmacological or placebo intervention in order to characterise the distribution of evoked hypersensitivity in a repeated intramuscular NGF injection pain model.

\section{Cohort 2 -double-blinded, placebo-controlled minocycline trial}

Twenty subjects ( 7 females) were recruited within this arm of the study. No subjects from cohort 1 were recruited into this arm of the study due to their familiarity with the NGF pain model. The subjects were randomly allocated to a drug treatment group to assess the efficacy of minocycline in ameliorating or preventing NGF induced muscle hyperalgesia.

Participants were randomly allocated (10 in each group) to either receive treatment (minocycline) in week 1 and placebo (rice flour) in week 2 (M1/P2; 8 males, 2 females), or placebo in week 1 and treatment in week 2 (P1/M2; 5 males, 5 females). Subjects took their week 1 loading dose at the conclusion of the first testing and NGF injection session on day 0 and were instructed to start their bidaily dose that evening. The final dose from week 1 was consumed on the morning of day 7 , prior to PPT testing on that day, with subjects returning their empty week 1 drug container on this day to ensure compliance. After this, subjects were given their week 2 loading dose and instructed to undertake an identical protocol such that their final dose would be taken on the morning of day 14, prior to final PPT testing and completion of the study.

This article is protected by copyright. All rights reserved 
In order to avoid any expectation of treatment by the subjects, individuals within the drugcrossover study were informed that there were three potential groups they could be placed in, with one of those groups being a placebo-only group which in fact did not exist. This was in addition to being informed of the actual treatment groups in which subjects received minocycline treatment in the first week followed by placebo (M1/P2) or vice versa (P1/M2).

\section{Statistical analysis}

Within cohorts, a two-way repeated measures analysis of variance (2-way RM ANOVA) was used to compare the sensory threshold values (PPTs) obtained at days 0, 7 and 14 across the bilateral FCU testing sites. The P1/M2 and M1/P2 treatment groups from cohort 2 were compared with the untreated control group (cohort 1). When significant differences were observed on a group level, Tukey's multiple comparison test was performed to identify individual changes at different applied forces (N) during PPT testing.

D'Agostino and Pearson omnibus test was performed to confirm the presence of normally distributed data. Data are presented as mean \pm standard error of the mean (SEM).

Preliminary power calculations (G Power 3.1) based on the cumulative (maximal) pressure point thresholds using an RM-ANOVA (control, day 7, day 14 and recovery), with two experimental groups (P1/M2 and M1/P2), 9 participants $(\alpha=0.05)$ and a conservative effect size of 0.3 suggested a power of 0.84 . Minocycline reduced the NGF induced hypersensitivity by over $40 \%$ resulting in an effect size of 0.86 and power $>0.99$.

\section{Results}

\section{Cohort 1 - Untreated control}

Eleven subjects ( 4 females) were recruited within this arm of the study of which one subject (female) exhibited persistent muscle ache and muscular hypersensitivity covering the entirety of the 15 test sites and extending along the limb following two NGF injections. Consequently, the subject elected to not receive the third NGF injection. The subject undertook sensory testing throughout the duration of the study and a hypersensitivity did persist, however, the subject was excluded from analysis as she did not receive all NGF injections. Acutely, the injection of NGF was non-painful in 7 out of 10 subjects with the other 3 subjects reporting a transient ( $20 \mathrm{~s}$ ) sharp pain upon injection. This acute pain was 
not present at the first NGF injection and was only reported for the subsequent injections. None of the subjects (except for the one excluded) reported a persistent background pain within the FCU muscle at rest, but rather a pain to palpation or exertion of the muscle and adjacent musculoskeletal structures.

Under control conditions, at day 0 , the maximal force of $30 \mathrm{~N}$ produced no pain in all except two subjects where a single tender point (out of 15 test sites) was reported in each, resulting in an average of $0.3 \pm 0.2$ tender points reported across the cohort (Figure $2 \mathrm{~A}$ ). One week after the start of NGF injections (day 7), muscle hyperalgesia was maximal at the central injection site (marked in bold throughout Figure 2), where all individuals (100\%) reported a painful response, and was surrounded by test sites where progressively higher forces were required to evoke responses with two-thirds of all test sites ( $\mathbf{6 6 4 \%}$ : total number of responses divided by total number of trial sites (15) in 10 subjects $=96 / 150$ ) evoking a painful response at $30 \mathrm{~N}$.

When the spatial data were replotted as the cumulative number of tender points over the testing range $(5-30 \mathrm{~N})$, the use of $30 \mathrm{~N}$ resulted in the emergence of $10 \pm 0.9$ muscle sites as tender, a significant increase from day $0(p<0.0001)$. The minimal threshold values ranged between $5-15 \mathrm{~N}$ (mean $8.5 \pm 1.4 \mathrm{~N})$ and were associated with a significantly $(\mathrm{p}<0.0001)$ increased number of responses between 5 and $30 \mathrm{~N}$, indicating that the fall in threshold was accompanied by an increased sensitivity (left shift) in the subjects' pain response profile.

Consistent with ongoing recovery, the number of tender points at day 14 had fallen to $\mathbf{\Sigma} 3 \mathbf{3} \%$ of all tested sites with reduced responses at 20,25 and $30 \mathrm{~N}(3.3 \pm 0.9, p=0.0066 ; 4.7 \pm 1.2$, $p<0.0001 ; 5.7 \pm 1.4, p<0.0001$, respectively). The majority of subjects $(80 \%)$ reported minimum thresholds within the range of 5-20 N $(12.9 \pm 2.4 \mathrm{~N})$, a value which was significantly elevated from the minimum thresholds obtained at day $7(p=0.0118)$ yet was still significantly less than baseline (day 0$)$ values $(p<0.0001)$.

Follow up testing at least 28 days post the initial NGF injection revealed a complete return to normalcy in all subjects.

No changes were observed in the contralateral FCU following repeat NGF injection with 30 $\mathrm{N}$ force eliciting an average of $0.2 \pm 0.2$ tender points at day $0,0.3 \pm 0.2$ at day 7 and no tender points at day $14(p=0.2356)$. Given this constraint, only the effects of NGF injection 
within the ipsilateral limb will be discussed in further cohorts. The effects observed in the ipsilateral limb were not solely the result of wind-up phenomena associated with repeated testing as no change was observed when the same testing was used in the contralateral limb.

\section{*Insert Figure 2 here*}

\section{Cohort 2-double-blinded placebo-minocycline cross-over trial}

In total 20 subjects were recruited as part of this cohort, with subjects randomly allocated to either treatment group ( $n=10$ per group). Of the subjects randomly allocated into the $\mathrm{P} 1 / \mathrm{M} 2$ group, one subject (female) reported nausea and intestinal discomfort during the minocycline treatment phase and withdrew from the study. To account for an uneven cohort between the two treatment groups, a random number generator was used to exclude an individual (male) from the M1/P2 treatment group to allow for a comparative $n$ across both groups within this cohort (results $n=18$ ). Sequential analysis based on a subjectby-subject exclusion of one participant from this group did not alter the significance of these findings between groups.

Subjects within this cohort reported similar symptomology in response to NGF injection as cohort 1 with acute NGF injection remaining painless in the majority of subjects with a lack of tonic muscle pain in the injected region for the study duration, but rather a pain to exertion or palpation.

\section{P1/M2 PPT examination}

In those receiving the placebo first (P1), mapping the spatial extent of hypersensitivity revealed a pattern indistinguishable from that observed in the untreated group (cohort 1) at day 7 that was characterised by a high sensitivity (average minimum of $9.4 \pm 2.6 \mathrm{~N}$; range 5$25 \mathrm{~N})$ at the injection site where all subjects (100\%) reported pain, surrounded by sites of decreasing sensitivity and responsiveness (Figure $2 B$ ). Overall $\sim \boldsymbol{\Sigma} 64 \%$ of all test sites $(\mathbf{8 6} / \mathbf{1 3 5}$ total sites) displayed a response at $\leq 30 \mathrm{~N}$. A two-way RM ANOVA of the cumulative number of tender points indicated that placebo had no effect on the spatial extent or intensity of muscle hypersensitivity at day 7 compared to the untreated cohort with $10 \pm 0.6$ points being reported as tender at $\leq 30 \mathrm{~N}(p<0.0001)$ and elevated response levels at forces of 10 - 
$30 \mathrm{~N}(\mathrm{p}<0.005)$. When the same participants received minocycline in the second week $(M 2)$, fewer individuals responded (67\%) at the central injection site (Figure 2B) with the number and sensitivity of responses at adjacent test sites declining more rapidly than that observed in their day 7 responses or those observed in the untreated week 2 groups (Figure 2A).

Overall the number of responsive sites was reduced to $\sim \Sigma \mathbf{2 2} \%$ or $3.1 \pm 0.9$ points at $\leq 30 \mathrm{~N}$, significantly fewer than those reported at the same time point in the untreated cohort (5.7 \pm 1.4 responses at $30 \mathrm{~N}, \mathrm{p}<0.05$.

Additionally, a significant reduction was observed between tender points observed at day 7 and 14 for forces of $10 \mathrm{~N}$ and greater $(\mathrm{p}<0.05)$, suggesting a functional recovery. The number of tender points at $30 \mathrm{~N}$ observed at baseline (day 0 ) and at day 14 were not significantly different $(p=0.0791)$.

\section{M1/P2 PPT examination}

In subjects who received minocycline treatment in week 1 (and placebo in week 2, M1/P2) a significant interaction $(p<0.0001)$ between the observed number of tender points at varying forces across the testing period (Figure 3 ) and treatment group was observed. At day 7 only $67 \%$ of subjects displayed threshold values in the testing range (mean $11.7 \pm 3.4 \mathrm{~N}$; range 5$20 \mathrm{~N}$ ) and the spatial extent of the hypersensitivity was confined to $\Sigma 36 \%(48 / 135)$ of all the tested sites (Figure 2C). Likewise, the cumulative data revealed significantly fewer tender points $(5.7 \pm 1.7$ at $\leq 30 \mathrm{~N})$ compared to untreated $(p=0.0019)$ and placebo-controlled groups ( $p=0.0053$ ) at this time point. The $5.7 \pm 1.7$ tender points reported to $30 \mathrm{~N}$ of force application represent an approximately $\mathbf{4 3 \%}$ decrease in reported cumulative tender points compared to both cohort 1 and the $\mathrm{P} 1 / \mathrm{M} 2$ treatment group at this time point which has been shown to be the peak of hypersensitivity. Measurements across all 15 sites at forces of $5 \mathrm{~N}$ and $10 \mathrm{~N}$ showed no significant differences ( $p>0.05$ ) in week 1 when compared to baseline (day 0$)$.

Contrastingly, comparisons between the PPT values obtained at day 14 and baseline show no significant variation ( $p>0.05$ ) across all applied force levels. However, significant variation was seen between day 7 and 14 measurements at $25 \mathrm{~N}(p=0.0225)$ and $30 \mathrm{~N}(p=0.0036)$.

\footnotetext{
*Insert Figure 3 here*
} 


\section{Day 14 data as a function of peak sensitivity (day 7)}

When data obtained at day 14 are represented as a function of the peak sensitivity reported at day 7 , a significant difference is observed between the M1/P2 and P1/M2 treatment groups in comparison to the untreated controls. The $\mathrm{P} 1 / \mathrm{M} 2$ treatment had a significantly increased amelioration of muscle tender points by day 14 as compared to the M1/P2 group $(p=0.0003)$. This is evident at $30 \mathrm{~N}$ with the $\mathrm{P} 1 / \mathrm{M} 2$ only reporting $37 \pm 8 \%$ of the tender points reported at day 7 as still being tender at day 14 while the M1/P2 group still reported $60 \pm 11 \%$ of the day 7 tender points as painful at day 14 testing. The response of the M1/P2 group at day 14 is similar to the response of the untreated control cohort which reported 62 $\pm 11 \%$ of the day 7 tender points as still painful at day 14 . Thus, despite minocycline significantly reducing overall tender points at day 7 in the M1/P2 treatment group, the switch to placebo in the second week of the study results in the same subsequent recovery from peak hypersensitivity as a lack of treatment.

\section{Discussion}

In this study we characterised the sensory effects of repeated intramuscular NGF injections in healthy subjects, revealing a robust muscle hypersensitivity (hyperalgesia) that extended to all 15 test sites overlying the FCU (NGF affected muscle). This NGF-induced hypersensitivity did not extend to contralateral test sites, in contrast to observations following repeated HS injections (Samour et al., 2017). In the current placebo-controlled double-blind drug-crossover trial, minocycline was found to significantly reduce the onset of muscle hyperalgesia when given concurrently with NGF injection (M1/P2) and was equally able to alleviate muscular hypersensitivity when administered after peak muscle hyperalgesia (P1/M2). This extends our previous finding that minocycline ameliorates the development of muscle hyperalgesia when administered concurrent to the induction of HSinduced muscular pain hypersensitivity (Samour et al., 2017).

Progressive muscular hyperalgesia was observed in the NGF injection site with significantly decreased PPTs in all subjects regardless of the timing of minocycline intervention. This mechanical hyperalgesia manifested as an increase in the distribution and number of tender points across the affected FCU muscle and in adjacent muscles, peaking at day 7 and persisting through to the week 2 testing session. The hyperalgesia spread across the entirety 
of the compartment, despite the use of a single injection site. A somatopically diffuse region of pain hypersensitivity evoked by bolus intramuscular NGF injection has been reported before in the context of contraction-induced muscle pain (Sorensen et al., 2018). The finding of a spatially diffuse distribution of hypersensitivity from repeated bolus NGF injection suggests that this model could be used in future experimental studies of prolonged muscle pain and hyperalgesia.

The finding of muscle hyperalgesia mimics the diffuse muscle pain hypersensitivity commonly observed in chronic musculoskeletal pain conditions such as lateral epicondylitis (tennis elbow), temporomandibular joint disorders and fibromyalgia (Andersen et al., 2008; Bergin et al., 2015; Gerber et al., 2011; Hayashi et al., 2013; Svensson et al., 2003). Indeed, the lack of contralateral interactions observed in the NGF pain model has also been described previously (Svensson et al., 2008), however, this was in response to a single intramuscular injection of $5 \mu \mathrm{g}$ of NGF. This does provide a point of contrast to the HS pain model where bilateral interactions have been shown in an experimental design which had an identical time course to this study (Samour et al., 2017). A key difference between the two experimental models may be the inherently painful nature of HS injection which consistently is able to evoke an acutely painful percept, as opposed to the largely innocuous nature of acute NGF injection with only a minority of subjects reporting acute pain, however those subjects still exhibited no bilateral tenderness. Reports of acute pain from intramuscular NGF injection are varied with only a minority of papers reporting an acute sharp pain at the time of injection (Gerber et al., 2011; Hayashi et al., 2013). The lack of acute pain in other reported literature could be due to the single injection protocol which is favoured in the literature (Andersen et al., 2008; Bergin et al., 2015; Deising et al., 2012; Svensson et al., 2003; Svensson et al., 2008). It is possible the transient pain reported in some subjects is a result of the NGF vehicle with sterile water for BP typically having a pH between 5.5 and 7.5. Whilst intramuscular injection of acidic solutions is known to result in pain (Frey Law et al., 2008; Jensen and Norup 1992), the small injection volume used in this study $(50 \mu \mathrm{L})$ and the absence of acute pain following the first NGF injection indicates that this pain is more likely resultant from NGF evoked sensitisation. Additionally, pain was only elicited on repeat injections, with the primary injection of NGF remaining innocuous, further indicating that acute pain within this study is likely resultant from the progressive 
sensitisation of the NGF-injected region. Whether the presence of overt pain at the time of injection favours the development of a more profound and extensive pattern of pain hypersensitivity across limbs remains untested.

The most intriguing finding of this study is the ability of minocycline to significantly alleviate the muscle hyperalgesia associated with intramuscular NGF injections. This alleviation appears to be independent of the time of onset of mechanical hypersensitivity as beneficial effects were observed for the onset (M1/P2) and established (P1/M2) treatment groups. In subjects who received minocycline in the first week (M1/P2) there was a significant decrease in maximum tender points elicited at $30 \mathrm{~N}$ when tested on day 7 at peak hypersensitivity (Figure 2). There was an approximate reduction in the cumulative number of reported tender points of $\mathbf{4 3 \%}$ in this treatment group compared to the untreated cohort and the group which received placebo during week 1 (P1/M2). Accordingly, at this time point a reduced cumulative number of tender points correlated with a lesser degree of somatotopic spread across the anterior forearm (Figure 1). Additionally, in the P1/M2 treatment group, there was an enhanced amelioration of hypersensitivity between days 7 and 14 when compared to the other treatment groups who received either placebo or no treatment within this time period. Minocycline treatment led to $\mathbf{2 0 - 2 5 \%}$ fewer cumulative tender points at day 14 as a function of the tender points at day 7 , demonstrating a clear efficacious effect in the recovery of an already established muscular pain hypersensitivity.

Critical to the above findings, when subjects received a placebo during the induction of NGFevoked hypersensitivity (P1/M2) there were no differences in the first week from untreated controls, indicating a lack of placebo effect within this group. Similarly, cessation of treatment within a group who received minocycline for week 1 (M1/P2) resulted in identical recovery between weeks 1 and 2 as untreated controls, further indicating a lack of placebo effect across the study. We believe the reason for the absence of a placebo effect may be related to the study design, in particular how the expectations of the subjects were managed. In contrast to clinical trials (where the logical expectation is that treatment will alleviate existing pain, i.e., meeting the Latin derivation of placebo: I will please), this study used healthy subjects (cohort 2) that were naïve as to the impact of repeat NGF injections and the possible impact of minocycline (or indeed which agent, NGF or minocycline, was the stimulus and which was the treatment). The healthy subjects' sole task was to report which 
of the 15 PPT test sites were painful during each testing session. The subjects were informed that study design was a cross-over design with an equal likelihood of receiving placebo in the first week, second week or in both weeks. Previous studies examining the effects of minocycline on muscle hyperalgesia have reported a substantial placebo effect ( $35 \%)$, however, that may be due to the two-arm design of the study as subjects were informed that there were only two treatment allocations, minocycline or placebo (Samour et al., 2017). The use of a drug-crossover design in this study led to a lack of observable placebo effect and thus our findings suggest that minocycline treatment has an efficacious effect on muscle hyperalgesia.

The exact mechanism by which minocycline is exerting this effect is beyond the scope of our study, however, based on the available literature regarding minocycline and NGF, several interactions may be occurring. The glial suppressive effects of minocycline have been widely reported (Amin et al., 1996; Tikka et al., 2001; Tikka and Koistinaho 2001) and equally, it has been demonstrated that microglial activation is implicated in the cascade initiated by peripheral NGF administration (De Simone et al., 2007; Pezet and McMahon 2006). Indeed it has been concluded in multiple animal studies that the efficacious effects of minocycline on experimentally induced pain is the result of a corresponding decrease in microglial activation (Chew et al., 2014; Hua et al., 2005; Ledeboer et al., 2005; Raghavendra et al., 2003) and synaptic relay in the substantia gelatinosa (Huang et al., 2014; Peng et al., 2016). Minocycline has also been shown to suppress the interaction of primary afferent neurons with stellate cells (Afroz et al., 2019) and macrophages (Dutta et al., 2010) in the periphery. Whether the effect of minocycline in humans is the result of central or peripheral effects, or likely a combination of the two, warrants further investigation.

NGF has been shown to directly upregulate neurotrophic factors including SP (Lewin et al., 2014; Minnone et al., 2017; Pezet and McMahon 2006) which has long been regarded as necessary for the development of central sensitisation (Khasabov et al., 2002; Malcangio et al., 1997; Xu et al., 1992). The involvement of SP in the formation of the centralized effects of NGF was shown in isolated spinal cords where antagonism of SP significantly reduced NGF evoked responses (Thompson et al., 1995). Increased SP expression as a result of NGF could result in the activation of microglia which would further release inflammatory markers and thus contribute to central sensitisation (Kreutzberg 1996; Watkins et al., 2001). 
Additionally, retrograde transport of NGF along sensory terminals to trk-A positive neurons has been shown to activate the glutamatergic system with the phosphorylation of NMDA subunits (Pezet and McMahon 2006; Svensson et al., 2008). Furthermore, NMDA receptors in the periphery are known to modulate muscle nociceptor activity (Wong et al., 2014).

More broadly, aberrant glial cell activation has been implicated in the development of chronic pain conditions (Bettoni et al., 2008; Jha et al., 2012; Loggia et al., 2015; Nijs et al., 2017; Scholz and Woolf 2007). As such, the anti-microglial properties of minocycline have already been examined in a range of conditions including Parkinson's (Wu et al., 2002), multiple sclerosis (Popovic et al., 2002), spinal cord injury (Stirling et al., 2004) and Alzheimer's disease (Garcez et al., 2017; Seabrook et al., 2006). In animal models, minocycline has been shown to significantly reduce mechanical hyperalgesia (Boyette-Davis and Dougherty 2011; Boyette-Davis et al., 2011; Hua et al., 2005; Ledeboer et al., 2005; Morgado et al., 2011; Raghavendra et al., 2003). This efficacious effect of minocycline in mechanical hypersensitivity has been somewhat less convincing in human studies with the beneficial effects reported in conditions including rheumatoid arthritis (Langevitz et al., 2000), spinal cord injury (Casha et al., 2012) and diabetic neuropathy (Syngle et al., 2014) matched by reports of non-efficacious or even detrimental effects in a range of other conditions (Arout et al., 2018; Curtin et al., 2017; Pachman et al., 2017; Sumitani et al., 2016; Vanelderen et al., 2015). Intriguingly the lack of efficacy in pain alleviation may come down to study design with many using qualitative measures in the absence of acute stimuli (Curtin et al., 2017; Pachman et al., 2017; Sumitani et al., 2016; Vanelderen et al., 2015) whilst others use supramaximal stimuli (Arout et al., 2018) that are and should reasonably remain painful; in contrast those used in the current study traversed a range of intensities that were innocuous under control conditions but became painful following repeated NGF injections.

The sex imbalance within this study stands as a potential limitation with only approximately a third of the study participants being female. This imbalance is an important consideration due to a higher prevalence of chronic pain in females (Bartley and Fillingim 2013). However, more pertinent to the findings of the current study is whether sex has a role in the efficacy of minocycline for the treatment of pain. There are conflicting reports on this in the mouse literature with initial evidence suggesting that how effective minocycline was on alleviating 
pain were sex-independent (Bastos et al., 2013), though, more recent reports have concluded that minocycline is more efficacious in males (Chen et al., 2018; Fernandez-Zafra et al., 2019). However, such observations in humans remain untested, necessitating further investigation if minocycline is to be considered for the alleviation of clinical pain.

\section{Conclusions}

Minocycline significantly reduced the muscle hyperalgesia evoked by NGF when administered concurrently with NGF injections and pain hypersensitivity development. Additionally, when minocycline was administered following the establishment of muscle hyperalgesia, it was able to significantly and efficaciously facilitate recovery compared to untreated and placebo counterparts. The data obtained in this study demonstrate that giving minocycline pre-emptively or following the onset of muscle tenderness reduces muscle hyperalgesia.

\section{Acknowledgements}

The authors would like to acknowledge Bob Harrison Soul Pattinson Chemist (Miranda, Australia) for the compounding of substances used in this study and for the retention of the participant code for the duration of this study.

\section{Author Contributions}

SSN and DAM made substantial contributions to the study design and conception. JSD was responsible for data acquisition and analysis as well as drafting the original manuscript. The manuscript was subsequently revised critically for important intellectual content by SSN and DAM before all authors approved the final manuscript before submission for publication.

\section{Legends}

Figure 1. Study design across the untreated and double-blind placebo-controlled minocycline crossover with injection and PPT test sites. A timeline depicting NGF injections and PPT testing sessions across the two-week study duration. In the placebo-controlled, cross-over study participants were randomly assigned to start (day 0 ) with placebo (P1/M2) or minocycline (M1/P2) and switch to minocycline/placebo, respectively on day 7. PPTs were measured before (days 0 and 7) subjects took a 200mg loading dose (grey) and provided with continuation doses (100mg bidaily for 7 days, green). Final PPT testing was conducted 
on day 14. The test sites (black dots) and NGF injection site (red dot) are shown in the lower figurine.

Figure 2. Spatial distribution (\% of subjects with a threshold $\leq 30 \mathrm{~N}$ ) and average pressure pain thresholds (PPT, coloured scale) prior to (day 0, control), 7 and 14 days after the start of repeat NGF injections, and their improvement following minocycline treatment. Average PPTs are coded from red $(5 \mathrm{~N})$ to white $(30 \mathrm{~N})$. Each square corresponds to a test site overlying the FCU muscle as shown in Figure 1. Sites where no PPTs were recorded within our test range (i.e. PPT >30N) are marked with an X. A. Untreated subjects $(n=10): 7$ days after the first NGF injection, mechanical hyperalgesia focused on the central injection site (marked in bold) was reported by all (100\%) and extended to two-thirds ( $\mathbf{6 6 4 \% )}$ of sites tested (10 subjects $\times 15$ sites: 96/150); 14 days following repeat NGF, 67\% of subjects reported hyperalgesia that was confined to $\mathbf{\Sigma} \mathbf{3 3} \%$ of all sites tested. B. Subjects treated with placebo first (P1/M2, n=9) were indistinguishable from untreated subjects at day 7 but showed enhanced recovery (elevated thresholds and fewer tender points, $\mathbf{\Sigma 2 2} \%$ ) following minocycline treatment at day 14 . C. Subjects treated with minocycline first (M1/P2, n=9) developed a reduced hypersensitivity (at day 7) that was comparable to that observed in the recovery (day 14) of untreated and $\mathrm{P} 1 / \mathrm{M} 2$ groups.

Figure 3. Muscle tender points (mean \pm SEM) reported across an NGF-injected FCU in control and minocycline treated cohorts. The untreated control group (cohort 1) received no treatment $(n=10)$. In the treatment groups, one group $(n=9)$ received minocycline until day 7 before receiving placebo in week $2(M 1 / P 2)$ while the other $(n=9)$ received placebo followed by minocycline (P1/M2). The day 0 recordings were obtained prior to NGF injection and show no statistical variation between groups. The statistical variance was observed between the untreated control group and the M1/P2 group at the end of week 1 and persisted until week 2 at higher forces. No placebo effect was observed at week 1 in the P1/M2 group, however, retrospective minocycline treatment resulted in significantly reduced tenderness at $30 \mathrm{~N}$ in this group. Total $\mathrm{n}=28$.

\section{References}

This article is protected by copyright. All rights reserved 
Afroz S, Arakaki R, Iwasa T, Oshima M, Hosoki M, Inoue M, Baba O, Okayama Y, Matsuka Y. CGRP Induces Differential Regulation of Cytokines from Satellite Glial Cells in Trigeminal Ganglia and Orofacial Nociception. Int J Mol Sci 2019;20: 10.3390/ijms20030711:10.3390/ijms20030711.

Aloe L, Tuveri MA, Carcassi U, Levi-Montalcini R. Nerve growth factor in the synovial fluid of patients with chronic arthritis. Arthritis Rheum 1992;35: 351-355, 10.1002/art.1780350315:10.1002/art.1780350315.

Amano T, Yamakuni T, Okabe N, Sakimura K, Takahashi Y. Production of nerve growth factor in rat skeletal muscle. Neurosci Lett 1991;132: 5-7, 10.1016/0304-3940(91)90418s:10.1016/0304-3940(91)90418-s.

Amin AR, Attur MG, Thakker GD, Patel PD, Vyas PR, Patel RN, Abramson SB. A novel mechanism of action of tetracyclines: Effects on nitric oxide synthases. Proc Natl Acad Sci, U S A 1996;93: 14014-14019, 10.1073/pnas.93.24.14014:10.1073/pnas.93.24.14014.

Andersen H, Arendt-Nielsen L, Svensson P, Danneskiold-Samsøe B, Graven-Nielsen T. Spatial and temporal aspects of muscle hyperalgesia induced by nerve growth factor in humans. Exp Brain Res 2008;191: 371-382, 10.1007/s00221-008-1531$5: 10.1007 / \mathrm{s} 00221-008-1531-5$.

Arout CA, Waters AJ, MacLean RR, Compton P, Sofuoglu M. Minocycline does not affect experimental pain or addiction-related outcomes in opioid maintained patients. Psychopharmacology 2018: 10.1007/s00213-018-5146-7:10.1007/s00213-018-51467.

Bartley EJ and Fillingim RB. Sex differences in pain: a brief review of clinical and experimental findings. Br J Anaesth 2013;111: 52-58, 10.1093/bja/aet127:10.1093/bja/aet127.

Bastos LF, Prazeres JD, Godin AM, Menezes RR, Soares DG, Ferreira WC, Dutra MM, Machado RR, Coelho MM. Sex-independent suppression of experimental inflammatory pain by minocycline in two mouse strains. Neurosci Lett 2013;553: 110-114, 10.1016/j.neulet.2013.08.026:10.1016/j.neulet.2013.08.026.

Bergin MJG, Hirata R, Mista C, Christensen SW, Tucker K, Vicenzino B, Hodges P, GravenNielsen T. Movement evoked pain and mechanical hyperalgesia after intramuscular 
injection of nerve growth factor: A model of sustained elbow pain. Pain Medicine 2015;16: 2180-2191, 10.1111/pme.12824:10.1111/pme.12824.

Bettoni I, Comelli F, Rossini C, Granucci F, Giagnoni G, Peri F, Costa B. Glial TLR4 receptor as new target to treat neuropathic pain: Efficacy of a new receptor antagonist in a model of peripheral nerve injury in mice. Glia 2008;56: 1312-1319, 10.1002/glia.20699:10.1002/glia.20699.

Boyette-Davis J and Dougherty PM. Protection against oxaliplatin-induced mechanical hyperalgesia and intraepidermal nerve fiber loss by minocycline. Exp Neurol 2011;229: 353-357, 10.1016/j.expneurol.2011.02.019:10.1016/j.expneurol.2011.02.019.

Boyette-Davis J, Xin W, Zhang H, Dougherty PM. Intraepidermal nerve fiber loss corresponds to the development of taxol-induced hyperalgesia and can be prevented by treatment with minocycline. Pain 2011;152: 308-313, 10.1016/j.pain.2010.10.030:10.1016/j.pain.2010.10.030

Brogden R, Speight T, Avery G. Minocycline: a review of its antibacterial and pharamcokinetic properties and therapeutic use. Drugs 1975;9: 251-291, 10.2165/00003495-197509040-00005:10.2165/00003495-197509040-00005.

Casha S, Zygun D, D. MM, Bains I, Yong VW, Hurlbert RJ. Results of a phase II placebocontrolled randomized trial of minocycline in acute spinal cord injury. Brain 2012;135: 1224-1236, 10.1093/brain/aws072:10.1093/brain/aws072.

Chen G, Luo X, Qadri MY, Berta T, Ji RR. Sex-Dependent Glial Signaling in Pathological Pain: Distinct Roles of Spinal Microglia and Astrocytes. Neurosci Bull 2018;34: 98-108, 10.1007/s12264-017-0145-y:10.1007/s12264-017-0145-y.

Chesterton LS, Barlas P, Foster NE, Baxter GD, Wright CC. Gender differences in pressure pain threshold in healthy humans. Pain 2003;101: 259-266, 10.1016/s03043959(02)00330-5:10.1016/s0304-3959(02)00330-5.

Chew DJ, Carlstedt T, Shortland PJ. The effects of minocycline or riluzole treatment on spinal root avulsion-induced pain in adult rats. J Pain 2014;15: 664-675, 10.1016/j.jpain.2014.03.001:10.1016/j.jpain.2014.03.001.

Curtin CM, Kenney D, Suarez P, Hentz VR, Hernandez-Boussard T, Mackey S, Carroll IR. A Double-Blind Placebo Randomized Controlled Trial of Minocycline to Reduce Pain 
After Carpal Tunnel and Trigger Finger Release. J Hand Surg Am 2017;42: 166-174, 10.1016/j.jhsa.2016.12.011:10.1016/j.jhsa.2016.12.011.

De Simone R, Ambrosini E, Carnevale D, Ajmone-Cat MA, Minghetti L. NGF promotes microglial migration through the activation of its high affinity recpetor: modulation of TGF-beta. J Neuroimmunol 2007;190: 53-60, 10.1016/j.jneuroim.2007.07.020:10.1016/j.jneuroim.2007.07.020.

Deising S, Weinkauf B, Blunk J, Obreja O, Schmelz M, Rukwied R. NGF-evoked sensitization of muscle fascia in humans. Pain 2012;153: 1673-1679, 10.1016/j.pain.2012.04.033:10.1016/j.pain.2012.04.033.

Dutta K, Mishra MK, Nazmi A, Kumawat KL, Basu A. Minocycline differentially modulates macrophage mediated peripheral immune response following Japanese encephalitis virus infection. Immunobiology 2010;215: 884-893, 10.1016/j.imbio.2009.12.003:10.1016/j.imbio.2009.12.003.

Fernandez-Zafra T, Gao T, Jurczak A, Sandor K, Hore Z, Agalave NM, Su J, Estelius J, Lampa J, Hokfelt T, Wiesenfeld-Hallin Z, Xu X, Denk F, Svensson Cl. Exploring the transcriptome of resident spinal microglia after collagen antibody-induced arthritis. Pain 2019;160: 224-236, 10.1097/j.pain.0000000000001394:10.1097/j.pain.0000000000001394.

Frey Law LA, Sluka KA, McMullen T, Lee J, Arendt-Nielsen L, Graven-Nielsen T. Acidic buffer induced muscle pain evokes referred pain and mechanical hyperalgesia in humans. Pain 2008;140: 254-264, 10.1016/j.pain.2008.08.014:10.1016/j.pain.2008.08.014.

Garcez ML, Mina F, Bellettini-Santos T, Carneiro FG, Luz AP, Schiavo GL, Andrighetti MS, Scheid MG, Bolfe RP, Budni J. Minocycline reduces inflammatory parameters in the brain structures and serum and reverses memory impairment caused by the administration of amyloid beta (1-42) in mice. Prog Neuropsychopharmacol Biol Psychiatry 2017;77: 23-31, 10.1016/j.pnpbp.2017.03.010:10.1016/j.pnpbp.2017.03.010.

Gerber RKH, Nie H, Arendt-Nielsen L, Curatolo M, Graven-Nielsen T. Local pain and spreading hyperalgesia induced by intramuscular injection of nerve growth factor are not reduced by local anesthesia of the muscle. Clin J Pain 2011;27: 240-247, 10.1097/AJP.0b013e3182048481:10.1097/AJP.0b013e3182048481.

This article is protected by copyright. All rights reserved 
Giovengo SL, Russell JJ, Larson AA. Increased concentrations of nerve growth factor in cerebrospinal fluid of patients with fibromyalgia. J Rheumatol 1999;26: 1564-1569.

Halliday DA, Zettler C, Rush RA, Scicchitano R, McNeil JD. Elevated nerve growth factor levels in the synovial fluid of patients with inflammatory joint disease. Neurochem Res 1998;23: 919-922, 10.1023/a:1022475432077:10.1023/a:1022475432077.

Hayashi K, Ozaki N, Kawakita K, Itoh K, Mizumura K, Furukawa K, Yasui M, Hori K, Yi SQ, Yamaguchi T, Sugiura Y. Involvement of NGF in the rat model of persistent muscle pain associated with taut band. J Pain 2011;12: 1059-1068, 10.1016/j.jpain.2011.04.010:10.1016/j.jpain.2011.04.010.

Hayashi K, Shiozawa S, Ozaki N, Mizumura K, Graven-Nielsen T. Repeated intramuscular injections of nerve growth factor induced progressive muscle hyperalgesia, facilitated temporal summation, and expanded pain areas. Pain 2013;154: 23442352, 10.1016/j.pain.2013.07.007:10.1016/j.pain.2013.07.007.

Hefti FF, Rosenthal A, Walicke PA, Wyatt S, Vergara G, Shelton DL, Davies AM. Novel class of pain drugs based on antagonism of NGF. Trends Pharmacol Sci 2006;27: 85-91, 10.1016/j.tips.2005.12.001:10.1016/j.tips.2005.12.001.

Herrero JF, Laird JM, Lopez-Garcia JA. Wind-up of spinal cord neurones and pain sensation: much ado about something? Prog Neurobiol 2000;61: 169-203, 10.1016/s03010082(99)00051-9:10.1016/s0301-0082(99)00051-9.

Hua XY, Svensson $\mathrm{Cl}$, Matsui T, B. F, Yaksh TL, Webb M. Intrathecal minocycline attenuates peripheral inflammation-induced hyperalgesia by inhibiting p38 MAPK in spinal microglia. Eur J Neurosci 2005;22: 2431-2440, 10.1111/j.14609568.2005.04451.x:10.1111/j.1460-9568.2005.04451.x.

Huang CY, Chen YL, Li AH, Lu JC, Wang HL. Minocycline, a microglial inhibitor, blocks spinal CCL2-induced heat hyperalgesia and augmentation of glutamatergic transmission in substantia gelatinosa neurons. J Neuroinflammation 2014;11: 7, 10.1186/1742-209411-7:10.1186/1742-2094-11-7.

Jensen $\mathrm{K}$ and Norup M. Experimental muscle pain in human temporal muscle induced by hypertonic saline, potassium and acidity. Cephalagia 1992;12: 101-106, 10.1046/j.1468-2982.1992.1202101.x:10.1046/j.1468-2982.1992.1202101.x.

Jha MK, Jeon S, Suk K. Glia as a link between neuroinflammation and neuropathic pain. Immune Netw 2012;12: 41-47, 10.4110/in.2012.12.2.41:10.4110/in.2012.12.2.41.

This article is protected by copyright. All rights reserved 
Khasabov SG, Rogers SD, Ghilardi JR, Peters CM, Mantyh PW, Simone DA. Spinal neurons that possess the substance $P$ receptor are required for the development of central sensitization. J Neurosci 2002;22: 9086-9098, 10.1523/JNEUROSCI.22-2009086.2002:10.1523/JNEUROSCI.22-20-09086.2002.

Kielian T, Esen N, Liu S, Phulwani NK, Syed MM, Phillips N, Nishina K, Cheung AL, Schwartzman JD, Ruhe JJ. Minocycline modulates neuroinflammation independently of its antimicrobial activity in Staphylococcus aureus-induced brain abscess. Am J Pathol 2007;171: 1199-1214, 10.2353/ajpath.2007.070231:10.2353/ajpath.2007.070231.

Kreutzberg GW. Microglia: A sensor for pathological events in the CNS. Trends Neurosci 1996;19: 312-318, 10.1016/0166-2236(96)10049-7:10.1016/0166-2236(96)10049-7. Kumar V and Mahal BA. NGF - the TrkA to successful pain treatment. J Pain Res 2012;5: 279287, 10.2147/JPR.S33408:10.2147/JPR.S33408.

Langevitz P, Livneh A, Bank I, Pras M. Benefits and risk of minocycline in rheumatoid arthritis. Drug Saf 2000;22: 405-414, 10.2165/00002018-20002205000007:10.2165/00002018-200022050-00007.

Ledeboer A, Sloane EM, Milligan ED, Frank MG, Mahony JH, Maier SF, Watkins LR. Minocycline attenuates mechanical allodynia and proinflammatory cytokine expression in rat models of pain facilitation. Pain 2005;115: 71-83, 10.1016/j.pain.2005.02.009:10.1016/j.pain.2005.02.009.

Lewin GR, Lechner SG, St. John Smith E. Nerve growth factor and nociception: From experimental embryology to new analgesic therapy. In: Neurotrophic Factors. Springer-Verlag Berlin Heidelberg; 2014; 251-282, 10.1007/978-3-642-45106-5_10. Loggia ML, Chonde DB, Akeju O, Arabasz G, Catana C, Edwards RR, Hill E, Hsu S, IzquierdoGarcia D, Ji RR, Riley M, Wasan AD, Zürcher NR, Albrecht DS, Vangel MG, Rosen BR, Napadow V, Hooker JM. Evidence for brain glial cell activation in chrnoic pain patients. Brain 2015;138: 604-615, 10.1093/brain/awu377:10.1093/brain/awu377.

Malcangio M, Garrett NE, Cruwys S, Tomlinson DR. Nerve growth factor- and neurotrophin3 -induced changes in nociceptive threshold and the release of substance $P$ from the rat isolated spinal cord. J Neurosci 1997;17: 8459-8469, 10.1523/JNEUROSCI.17-2108459.1997:10.1523/JNEUROSCI.17-21-08459.1997. 
Minnone G, De Benedetti F, Bracci-Laudiero L. NGF and its receptors on the regulation of the inflammatory response. Int J Mol Sci 2017;18: 1028, 10.3390/ijms18051028:10.3390/ijms18051028.

Moore RA. What works for whom? Determing the efficacy and harm of treatments for pain. Pain 2013;154: S77-86, 10.1016/j.pain.2013.03.024:10.1016/j.pain.2013.03.024. Morgado C, Pereira-Terra P, Cruz CD, Tavares I. Minocycline completely reverses mechanical hyperalgesia in diabetic rats through microglia-induced changes in the expression of the potassium chloride co-transporter 2 (KCC2) at the spinal cord. Diabetes Obes Metab 2011;13: 150-159, 10.1111/j.1463-1326.2010.01333.x:10.1111/j.14631326.2010.01333.x.

Murase S, Terazawa E, Queme F, Ota H, Matsuda T, Hirate K, Kozaki Y, Katanosaka K, Taquchi T, Urai H, Mizumura K. Bradykinin and nerve growth factor play pivotal roles in muscular mechanical hyperalgesia after exercise (delayed-onset muscle soreness). J Neurosci 2010;30: 3752-3761, 10.1523/JNEUROSCI.380309.2010:10.1523/JNEUROSCI.3803-09.2010.

Nagi SS and Mahns DA. C-tactile fibers contribute to cutaneous allodynia after eccentric exercise. J Pain 2013;14: 538-548, 10.1016/j.jpain.2013.01.009:10.1016/j.jpain.2013.01.009.

Nie H, Madeleine P, Arendt-Nielsen L, Graven-Nielsen T. Temporal summation of pressure pain during muscle hyperalgesia evoked by nerve growth factor and eccentric contractions. Eur J Pain 2009;13: 704-710, 10.1016/j.ejpain.2008.06.015:10.1016/j.ejpain.2008.06.015.

Nijs J, Loggia ML, Polli A, Moens M, Huysmans E, Goudman L, Meeus M, Vanderweeën L, Ickmans K, Clauw DJ. Sleep disturbances and severe stress as glial activators: key targets for treating central sensitization in chronic pain patients. Expert Opin Ther Targets 2017;21: 817-826, 10.1080/14728222.2017.1353603:10.1080/14728222.2017.1353603.

Pachman DR, Dockter T, Zekan PJ, Fruth B, Ruddy KJ, Ta LE, Lafky JM, Dentchev T, LeLindqwister NA, Sikov WM, Staff N, Beutler AS, Loprinzi CL. A pilot study of minocycline for the prevention of paclitaxel-associated neuropathy: ACCRU study RU221408I. Support Care Cancer 2017;25: 3407-3416, 10.1007/s00520-017-37602:10.1007/s00520-017-3760-2

This article is protected by copyright. All rights reserved 
Peng HZ, Ma LX, Lv MH, Hu T, Liu T. Minocycline enhances inhibitory transmission to substantia gelatinosa neurons of the rat spinal dorsal horn. Neuroscience 2016;319: 183-193, 10.1016/j.neuroscience.2016.01.047:10.1016/j.neuroscience.2016.01.047.

Pezet S and McMahon SB. Neurotrophins: Mediators and modulators of pain. Annu Rev Neurosci 2006;29: 507-538, 10.1146/annurev.neuro.29.051605.112929:10.1146/annurev.neuro.29.051605.1129 29.

Popovic N, Schubart A, Goetz BD, Zhang SC, Linington C, Duncan ID. Inhibition of autoimmune encephalomyelitis by a tetracycline. Ann Neurol 2002;51: 215-223, 10.1002/ana.10092:10.1002/ana.10092.

Priestley JV, Michael GJ, Averill S, Liu M, Willmott N. Regulation of nociceptive neurons by nerve growth factor and glial cell line derived neurotrophic factor. Can J Physiol Pharmacol 2002;80: 495-505, 10.1139/y02-034:10.1139/y02-034.

Raghavendra V, Tanga F, DeLeo JA. Inhibition of microglial activation attenuates the development but not existing hypersensitivity in a rat model of neuropathy. J Pharmacol Exp Ther 2003;306: 624-630, 10.1124/jpet.103.052407:10.1124/jpet.103.052407.

Raychaudhuri SK and Raychaudhuri SP. NGF and its receptor system: a new dimension in the pathogenesis of psoriasis and psoriatic arthritis. Ann N Y Acad Sci 2009;1173: 470477, 10.1111/j.1749-6632.2009.04652.x:10.1111/j.1749-6632.2009.04652.x.

Rukwied R, Mayer A, Kluschina O, Obreja O, Schley M, Schmelz M. NGF induces noninflammatory localized and lasting mechanical and thermal hypersensitivity in human skin. Pain 2010;148: 407-413, 10.1016/j.pain.2009.11.022:10.1016/j.pain.2009.11.022.

Samour MS, Nagi SS, Shortland PJ, Mahns DA. Minocycline prevents muscular pain hypersensitivity and cutaneous allodynia produced by repeated intramusuclar injections of hypertonic saline in healthy human participants. J Pain 2017;18: 9941005, 10.1016/j.jpain.2017.03.009:10.1016/j.jpain.2017.03.009.

Scholz $\mathrm{J}$ and Woolf $\mathrm{CJ}$. The neuropathic pain triad: neurons, immune cells and glia. Nat Neurosci 2007;10: 1361-1368, 10.1038/nn1992:10.1038/nn1992. 
Seabrook TJ, Jiang L, Maier M, Lemere CA. Minocycline affects microglia activation, Abeta deposition, and behavior in APP-tg mice. Glia 2006;53: 776-782, 10.1002/glia.20338:10.1002/glia.20338.

Sorensen LB, Boudreau SA, Gazerani P, Graven-Nielsen T. Enlarged Areas of Pain and Pressure Hypersensitivityby Spatially Distributed Intramuscular Injections ofLowDose Nerve Growth Factor. J Pain 2018:

10.1016/j.jpain.2018.11.005:10.1016/j.jpain.2018.11.005.

Stirling DP, Khodarahmi K, Liu J, McPhail LT, McBride CB, Steeves JD, Ramer MS, Tetzlaff W. Minocycline treatment reduces delayed oligodendrocyte death, attenuates axonal dieback, and improves functional outcome after spinal cord injury. J Neurosci 2004;24: 2182-2190, 10.1523/JNEUROSCI.5275-03.2004:10.1523/JNEUROSCI.527503.2004 .

Strauss JS, Krowchuk DP, Leyden JJ, Lucky AW, Shalita AR, Siegfried EC, Thiboutot DM, Van Voorhees AS, Beutner KA, Sieck CK. Guidelines of care for acne vulgaris management. J Am Acad Dermatol 2007;56: 651-663, 10.1016/j.jaad.2006.08.048:10.1016/j.jaad.2006.08.048.

Sumitani M, Ueda H, Hozumi J, Inoue R, Kogure T, Yamada Y, Kogure T. Minocycline does not decrease intensity of neuropathic pain intensity, but does improve its affective dimension. J Pain Palliat Care Pharmacother 2016;30: 31-35, 10.3109/15360288.2014.1003674:10.3109/15360288.2014.1003674.

Svensson P, Cairns BE, Wang K, Arendt-Nielsen L. Injection of nerve growth factor into human masseter muscle evokes long-lasting mechanical allodynia and hyperalgesia. Pain 2003;104: 241-247, 10.1016/s0304-3959(03)00012-5:10.1016/s03043959(03)00012-5.

Svensson P, Wang K, Arendt-Nielsen L. Effects of NGF-induced muscle sensitization on proprioception and nociception. Exp Brain Res 2008;189: 1-10, 10.1007/s00221-0081399-4:10.1007/s00221-008-1399-4.

Syngle A, Verma I, Krishan P, Garg N, Syngle V. Minocycline improves peripheral and autonomic neuropathy in type 2 diabetes: MIND study. Neurol Sci 2014;35: 1067$1073,10.1007 / s 10072-014-1647-2: 10.1007 / s 10072-014-1647-2$.

Thompson SW, Dray A, McCarson KE, Krause JE, Urban L. Nerve growth factor induces mechanical allodynia associated with novel A fibre-evoked spinal reflex activity and 
enhanced neurokinin-1 receptor activation in the rat. Pain 1995;62: 219-231, 10.1016/0304-3959(94)00271-f:10.1016/0304-3959(94)00271-f.

Tikka TM, Fiebich BL, Goldsteins G, Keinänen R, Koistinaho J. Minocycline, a tetracycline derivative, is neuroprotetcive against excitotoxicity by inhibiting activation and proliferation of microglia. J Neurosci 2001;21: 2580-2588, 10.1523/JNEUROSCI.2108-02580.2001:10.1523/JNEUROSCI.21-08-02580.2001.

Tikka TM and Koistinaho JE. Minocycline provides neuroprotection against N-methyl-Daspartate neurotoxicity by inhibiting microglia. J Immunol 2001;166: 7527-7533, 10.4049/jimmunol.166.12.7527:10.4049/jimmunol.166.12.7527.

Tsuda M. Microglia in the spinal cord and neuropathic pain. J Diabetes Investig 2016;7: 1726, 10.1111/jdi.12379:10.1111/jdi.12379.

Vanelderen P, van Zundert J, T. K, Pulaert M, De Vooght P, Mestrum R, Heylen R, Roubos E, Vissers K. Effect of minocycline on lumbar radicular neuropathic pain: A randomized, placebo-controlled, double-blind clinical trial with amitriptyline as a comparator. Anesthesiology 2015;122: 399-406, 10.1097/ALN.0000000000000508:10.1097/ALN.0000000000000508.

Watkins LR, Milligan ED, Maier SF. Glial activation: A driving force for pathological pain. Trends Neurosci 2001;24: 450-455, 10.1016/s0166-2236(00)01854-3:10.1016/s01662236(00)01854-3.

Watson JJ, Allen SJ, Dawbarn D. Targeting nerve growth factor in pain: what is the therapeutic potential? BioDrugs 2008;22: 349-359, 10.2165/0063030-20082206000002:10.2165/0063030-200822060-00002.

Weerakkody NS, Whitehead NP, Canny BJ, Gregory JE, Proske U. Large-fiber mechanoreceptors contribute to muscle soreness after eccentric exercise. J Pain 2001;2: 209-219, 10.1054/jpai.2001.22496:10.1054/jpai.2001.22496.

Wong H, Kang I, Dong X-D, Christidis N, Ernberg M, Svensson P, Cairns BE. NGF-induced mechanical sensitization of the masseter muscle is mediated through peripheral NMDA receptors. Neuroscience 2014;269: 232-244, 10.1016/j.neuroscience.2014.03.054:10.1016/j.neuroscience.2014.03.054.

Wu DC, Jackson-Lewis V, Vila M, Tieu K, Teismann P, Vadseth C, Choi DK, Ischiropoulos H, Przedborski S. Blockade of microglial activation is neuroprotective in the 1-methyl-4phenyl-1,2,3,6-tetrahydropyridine mouse model of Parkinson disease. J Neurosci 
2002;22: 1763-1771, 10.1523/JNEUROSCI.22-05-

01763.2002:10.1523/JNEUROSCI.22-05-01763.2002.

Xu XJ, Dalsgaard CJ, Wiesenfeld-Hallin Z. Spinal substance P and N-methyl-D-aspartate receptors are coactivated in the induction of central sensitization of the nociceptive flexor reflex. Neuroscience 1992;51: 641-648, 10.1016/0306-4522(92)90303j:10.1016/0306-4522(92)90303-j.

Yong VW, Wells J, Giuliani F, Casha S, Power C, Metz LM. The promise of minocycline in neurology. Lancet Neurol 2004;3: 744-751, 10.1016/S1474-4422(04)009378:10.1016/S1474-4422(04)00937-8.

Yrjänheikki J, Tikka T, Keinänen R, Goldsteins G, Chan PH, Koistinaho J. A tetracycline derivative, minocycline, reduces inflammation and protects against focal cerebral ischamia with a wide therapeutic window. Proc Natl Acad Sci, U S A 1999;96: 1349613500, 10.1073/pnas.96.23.13496:10.1073/pnas.96.23.13496. 


\section{Untreated Control}

Double blinded, placebo-controlled, cross-over trial

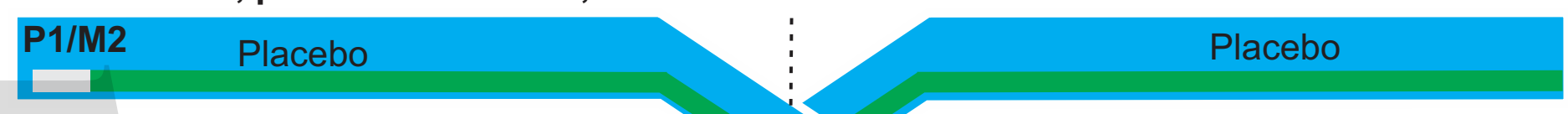

\section{M1/P2}

\section{Minocycline}
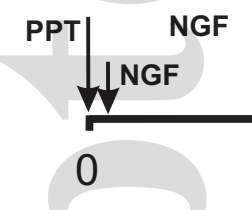

0
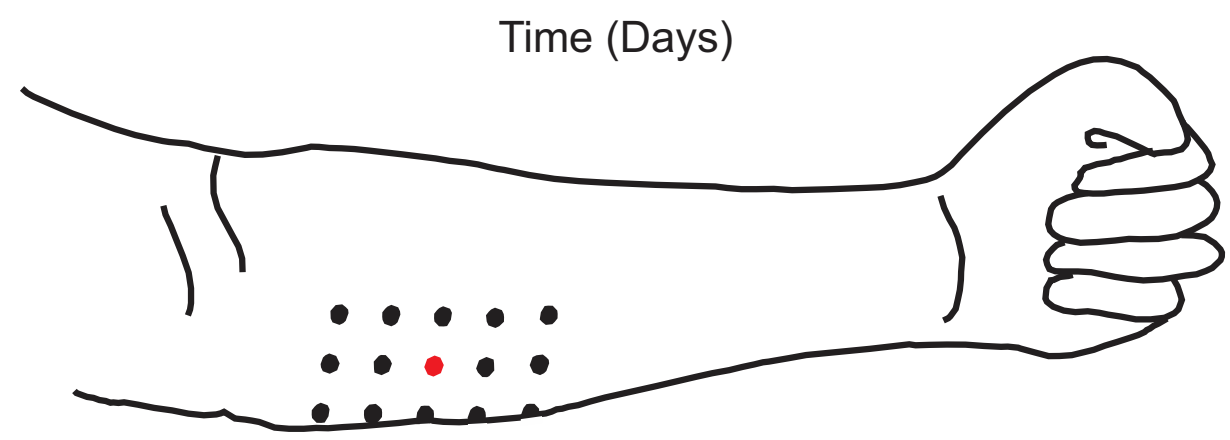

\section{Minocycline}

PPT

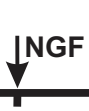
$J^{N G F}$
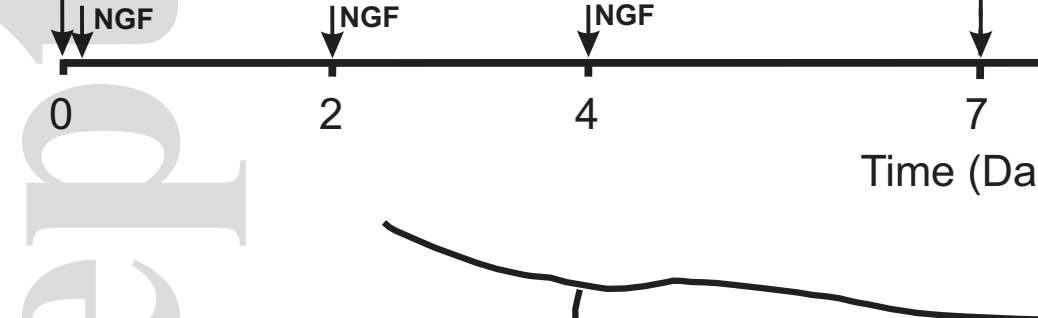


\section{Day 0 \\ (Control) \\ Day 7 \\ Day 14}

A. Untreated
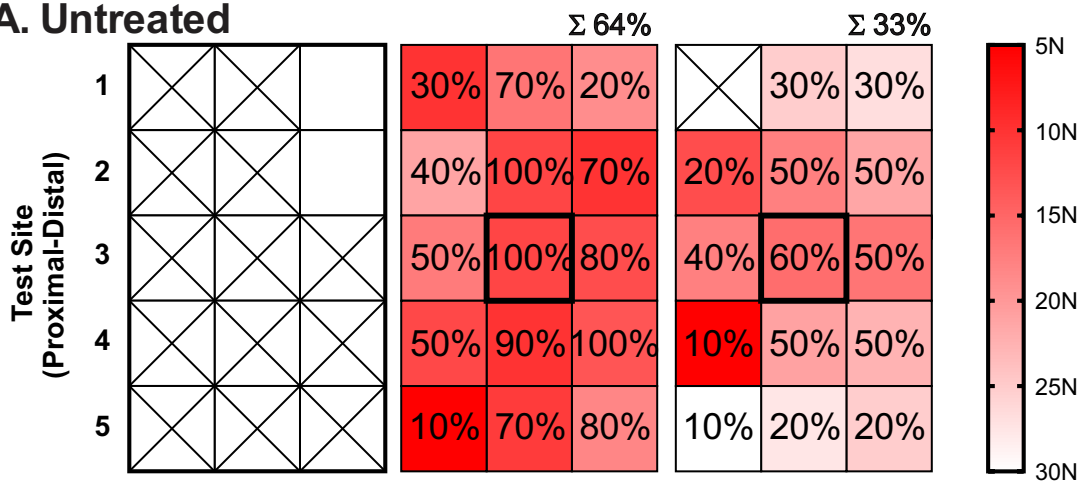

B. P1/M2
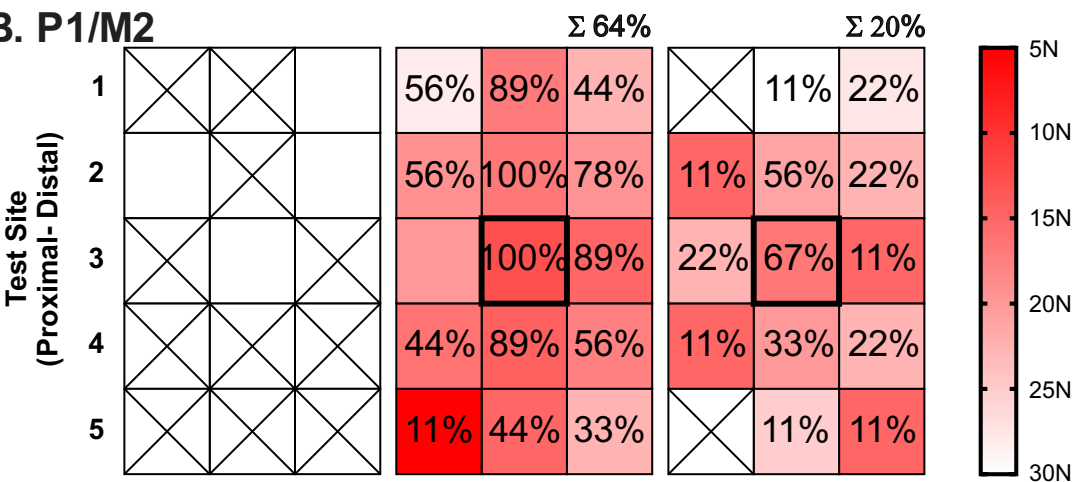

C. M1/P2
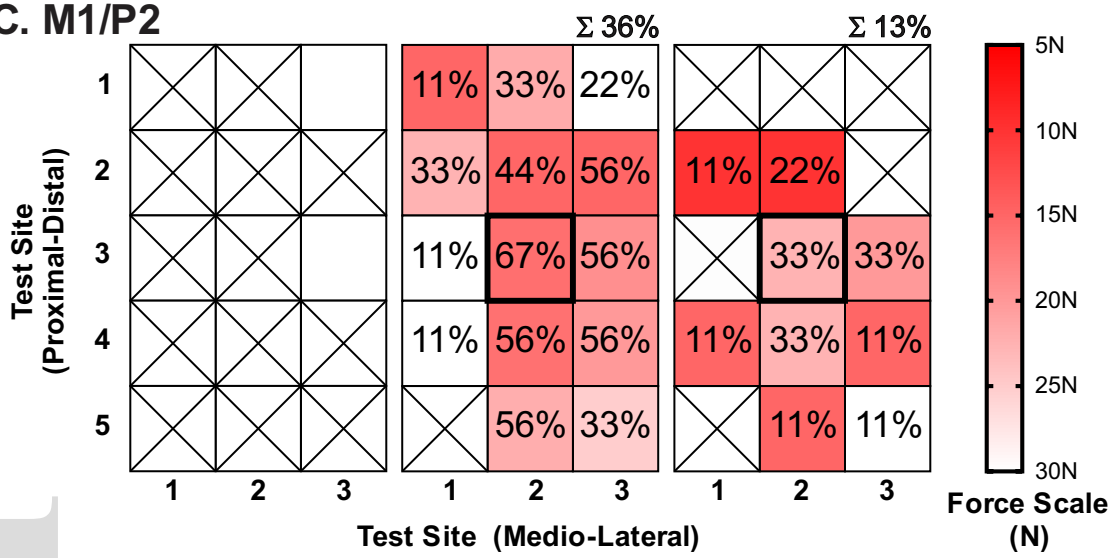

(N)

This article is protected by copyright. All rights reserved 
DAY 0
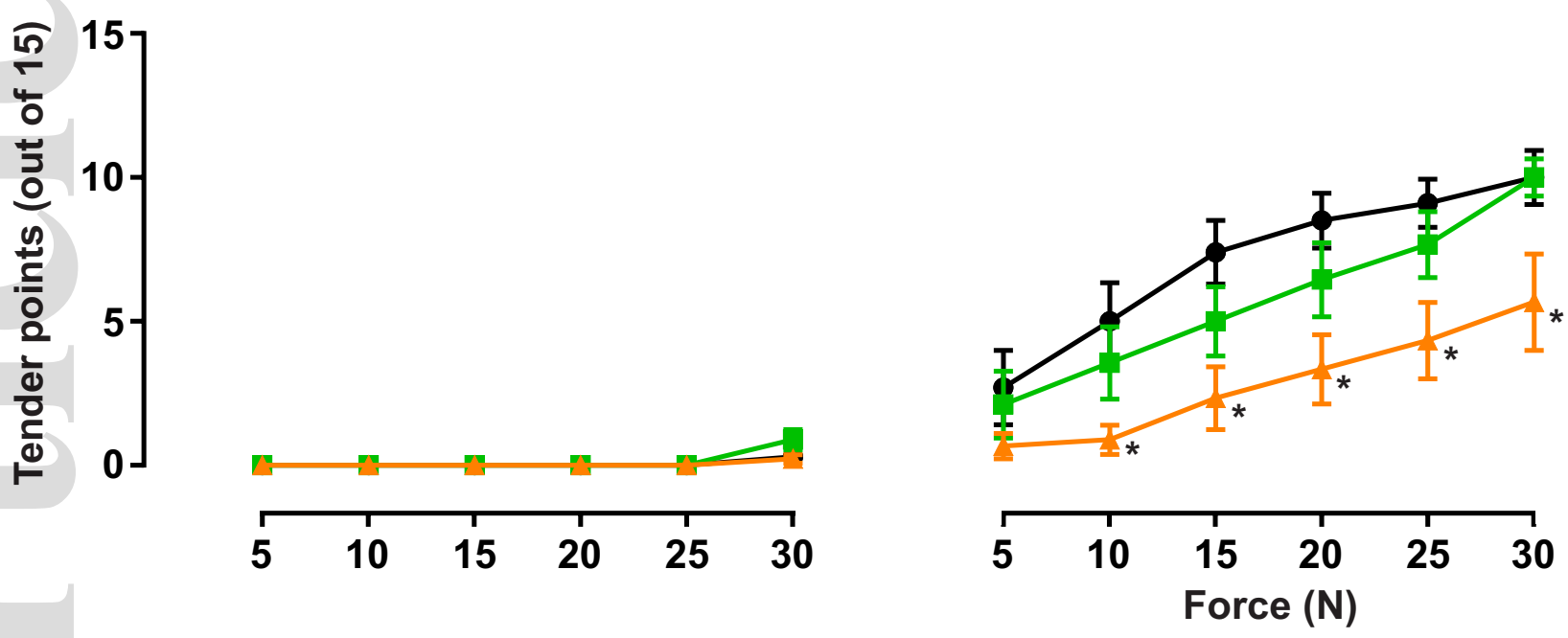

DAY 14
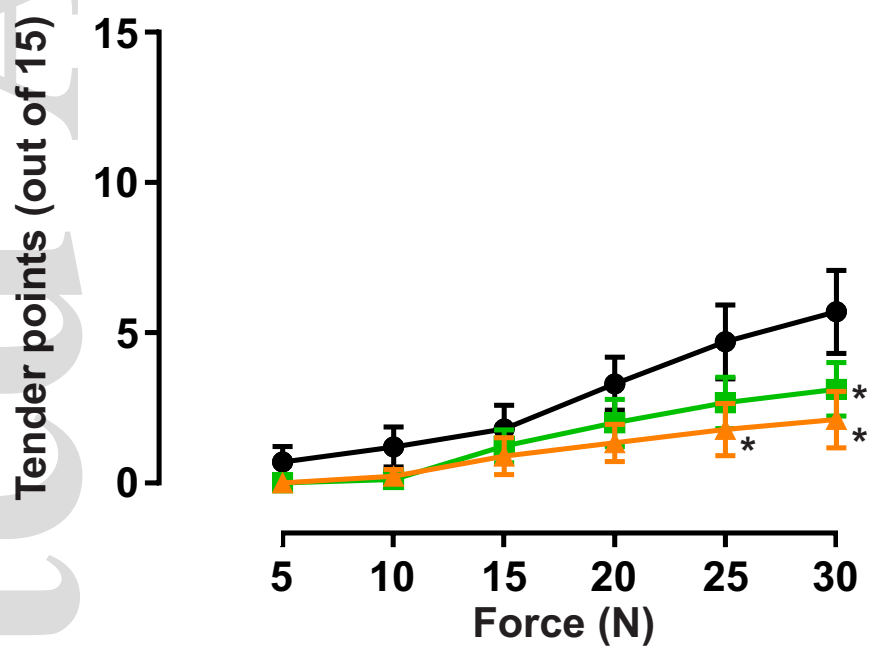

$\rightarrow$ UNTREATED

- P1/M2

$\leftarrow$ M1/P2 